\title{
Identification of gluten and major milk allergens Bos d 5 and Bos d 11 within commercially available honey.
}

\author{
Klekotko, $\mathrm{K}^{1}, \mathrm{M}$. Bermingham ${ }^{2}$, Maria Oliver $^{2}$, and J.A Blaxland ${ }^{1}$ \\ ${ }^{1}$ Cardiff Metropolitan University \\ ${ }^{2}$ InBio Ltd Vision Court Caxton Place Cardiff UK CF23 8HA
}

March 2, 2022

Title :Identification of gluten and major milk allergens Bos $d 5$ and Bos $d 11$ within commercially available honey.

To the Editor,

Although allergy to honey is rare, there have been documented systemic allergic reactions following ingestion of honey[1]. Interestingly, supplementary bee feeding with mixtures of soybean flour, dried brewer's yeast (containing high levels of residual gluten from brewing processes), and dry skimmed milk with sugar and water, can be implemented by beekeepers to maintain healthy honeybee colonies[2]. Additionally, there have been reports of mould contamination within beehives[3]. Both factors suggest a potential for gluten and allergenic protein presence in honey, which could account for some of the reported reactions following honey consumption. As such, the aim of this study was to determine if commercially available honey contained undeclared gluten and/or food or mould allergens, and at levels which could present a risk to individuals with hypersensitivities.

To investigate this, honey samples $(n=40)$ of UK, EU, Non-EU and blended Non-EU/EU origin were extracted and analysed for gluten using the R5 immunoassay and for major allergen content using quantitative multiplex arrays for allergens from cow's milk, egg, peanut, soy, hazelnut, cashew and moulds[4] (see online supporting material for methods) .

Of the forty samples analysed, it was observed that 11 of the 40 (27.5\%) samples contained gluten in the range of $2.5 \mathrm{ppm}$ to $13.8 \mathrm{ppm}$. Positive honey samples categorised by origin are detailed in Table 1 and Figure 1. Out of the 21 non-EU honey samples analysed, 7 were positive for gluten; forming $63.6 \%$ of the positive samples. From the $9 \mathrm{UK}$ and $9 \mathrm{EU} /$ non-EU blend honey samples, both had 2 samples positive for gluten, each accounting for $18.2 \%$ of the positive samples.

Milk allergens Bos d 5 and Bos d 11 were detected in $7 \%$ of samples. The positive results ranged from $0.368 \mathrm{mg} / \mathrm{kg}$, up to $0.567 \mathrm{mg} / \mathrm{kg}$ for Bos d 5 , and from $0.030 \mathrm{mg} / \mathrm{kg}$ up to $0.182 \mathrm{mg} / \mathrm{kg}$ for Bos d 11 ; with one sample being a blend of EU/Non-EU honey, and two being of UK origin. Samples found to contain Bos d 5 and Bos d 11 were also positive for gluten. Results of the 3 positive samples are shown in Table 1 and Figure 1. No detectable amounts of egg, peanut, soy, hazelnut, cashew or mould allergen was identified in the samples.

To our knowledge, this novel study is the first of its kind to identify the presence of milk allergen and gluten within honey. Consumers may take some reassurance in that levels of gluten detected in all samples fell below the current 20ppm 'gluten free' threshold[5]. Similarly, in the three samples positive for cow's milk allergens Bos d 5 and Bos d 11, the levels of milk allergen detected did not exceed the VITAL 3.0 reference dose of $0.2 \mathrm{mg}$ of milk protein per serving; a level that should prevent $99 \%$ of the allergic population from having a reaction[6] 
(see online supporting information for VITAL 3.0 calculations). However, for both milk allergen and gluten, caution may be required when considering repeated consumption, leading to accumulating doses. The fact that no allergen contaminants other than milk were identified in the honey samples can offer consumers further reassurances. Current literature does not give reason to suspect contamination from sources other than milk and soy, so it is encouraging the data shows agreement.

The findings herein could indicate honey suppliers may wish to undertake allergen testing of their products to offer greater safety to consumers. Moreover, it may be useful for future research to investigate the ability of allergen contaminants to be transferred from bee supplementary feeds to the final product to prevent possible accidental contamination of undeclared allergens.

WORD COUNT : 587

\section{References}

1. Aguiar, R., et al., Anaphylaxis caused by honey: a case report. Asia Pacific allergy, 2017. 7 (1): p. 48-50.

2. FERA, Feeding bees-pollen and substitutes, T.F.a.E.R. Agency, Editor. 2012.

3. Keller, K.M., et al., Fungi infection in honeybee hives in regions affected by Brazilian sac brood. Arquivo Brasileiro de Medicina Veterinária e Zootecnia, 2014. 66 : p. 1471-1478.

4. Filep, S. and M.D. Chapman, Doses of Specific Allergens in Early Introduction Foods for Prevention of Food Allergy. J Allergy Clin Immunol Pract, 2022. 10 (1): p. 150-158.e3.

5. Commission, E., Commission Implementing Regulation (EU) No 828/2014 of 30 July 2014 on the requirements for the provision of information to consumers on the absence or reduced presence of gluten in food 2014: Official Journal of the European Union.

6. Remington, B.C., et al., Updated population minimal eliciting dose distributions for use in risk assessment of 14 priority food allergens. Food Chem Toxicol, 2020. 139 : p. 111259.

\section{Authorship}

Klekotko, $\mathrm{K}+{ }^{1}$. Bermingham, M. D+${ }^{2}$, Oliver, M.A ${ }^{2}$, Blaxland, J.A ${ }^{1}$.

School of Health and Sport Sciences, Cardiff Metropolitan University, Llandaff, Cardiff, UK, CF5 2YU

InBio, Ltd, Vision Court, Caxton Place, Cardiff, UK, CF23 8HA

$+\mathrm{KK}$ and MDB contributed to this work equally

Corresponding Authors:

Dr Maria Oliver Dr James Blaxland

InBio, Ltd School of Sport and Health Sciences

Vision Court, Caxton Place Cardiff Metropolitan University

Cardiff, CF23 8HA Llandaff, Cardiff, CF5 2YU

UK UK

Tel: +442921674640 Tel: +4429 20416070

maria@indoorbiotech.co.ukJABlaxland@cardiffmet.ac.uk

Acknowledgements:

The authors thank Dr Martin Chapman (InBio, Inc) and Mr Ross Yarham (InBio, Ltd) for their helpful review of the work.

Funding 
This work was funded by Cardiff Metropolitan University and InBio, Ltd.

\section{Conflicts of Interest}

MDB and MAO are employees of InBio, Ltd. JB and KK declare no conflicts of interest.

Tables

Table 1. Measurement of gluten (gliadin) and milk allergens Bos d 5 and Bos d 11 in commercially available honey. Commercially available honey samples $(n=40)$ were analysed for gluten and allergen content. Sample results are reported as milligram of gluten (gliadin)/allergen per kilogram of honey $(\mathrm{mg} / \mathrm{kg})$. Samples are grouped by origin of production.

\begin{tabular}{llll}
\hline Honey Origin & Gluten (Gliadin) & Bos d 5 & Bos d 11 \\
\hline dNON-EU (7/21) & 6.10 & - & - \\
& 3.00 & - & - \\
& 11.00 & - & - \\
& 12.40 & - & - \\
& 13.80 & - & - \\
& 10.60 & - & - \\
UK (2/9) & 7.70 & - & - \\
EU/NON-EU (2/9) & 3.60 & 0.49 & 0.06 \\
EU (0/1) & 5.50 & 0.57 & 0.18 \\
\hline
\end{tabular}

\section{Figure Legend}

Figure 1. Measurement of Gluten, Bos d 5 and Bos d 11 in commercially available honey samples. Bos d $5\left(^{*}\right)$, Bos d $11\left(^{*}\right)$, and gluten $(*)$ levels are reported as milligram per kilogram of honey $(\mathrm{mg} / \mathrm{kg})$. Honey samples were grouped by origin of production to UK, EU, Non-EU and EU/Non-EU blend. Samples with no gluten/allergen content are excluded. Three samples were positive for gluten, Bos d 5 and Bos d 11 and are linked by data point shape; sample A (', sampleB(?), sampleC(?).Opensymbol (*)denotespositivedata forglutenonly.Specificvaluescanbe foundinTable1. 